\title{
A RE-EXAMINATION OF THE RELATIONSHIP BETWEEN ELECTRICITY CONSUMPTION AND ECONOMIC GROWTH IN NIGERIA
}

\author{
Inuwa Nasiru \\ Haruna Modibbo Usman \\ Abubakar Mohammed Saidu \\ Department of Economics, Faculty of Arts and Social Sciences, \\ Gombe State University, Gombe.
}

Doi: 10.19044/elp.v1no2a10 URL:http://dx.doi.org/10.19044/elp.v1no2a10

\begin{abstract}
This study investigates the long run and causality relationship between electricity consumption and economic growth in Nigeria during the period 1980-2011 via the application of Johansen's maximum likelihood cointegration technique and Granger causality tests based on vector error correction model (VECM). Based on the cointegration test results, it was found that electricity consumption has a long equilibrium relationship with economic growth. While, Granger causality test revealed unidirectional causality running from electricity consumption to economic growth in both the short and long run. Therefore, the results of this study showed clearly that electricity consumption plays an important role in the economic growth of Nigeria as any efforts to conserve electricity will have a negative repercussions on economic growth.
\end{abstract}

Keywords: Electricity consumption, Economic growth , Causality, Cointegration, Nigeria

\section{Introduction}

In the past three decades, several studies have been conducted to examine the relationship between electricity consumption and economic growth across developed and developing countries. The overall results show that there is a strong relationship between electricity consumption and economic growth. Some of these studies revealed unidirectional causality running from electricity consumption to economic growth (Ahmad Golam and Nazrul Islam, 2011; Kouakou, 2011; Akinlo, 2009; and Yuan et al. 2007), whereas some studies justified the other way round (Yoo and Kim, 
2006; Jumbe, 2004; Emeka, 2010; Nayaran and Smyth, 2005 and Shahbaz et al., 2011). In addition, bidirectional causality between electricity consumption and economic growth was also evidenced (Yoo, 2005; Odhiambo, 2009: and Tang, 2008).

However, The demand for infrastructure particularly electricity is growing rapidly in Nigeria, yet, for the past three decades, inadequate quantity and quality electricity services has been a regular feature in Nigeria, a country with 140 million people with a majority living on less than US\$2 a day. The electricity industry, dominated on the supply side by the stateowned electricity utility, National Electric Power Authority (NEPA), and succeeded by the Power Holding Company of Nigeria (PHCN), has been unable to provide and maintain acceptable minimum standards of service reliability, accessibility and availability (Iwayemi, 2008). The inefficiency as well as inadequate facilities to boost electricity supply has also been a major cause of the increasing gap between demand and supply of electricity. This could be due to the fact that there are only 9 working generating stations in Nigeria (3 hydro and 6 thermal) (Odularo and Okwonko, 2009).

It is not that no such study has been conducted to examine the relationship between electricity consumption and economic growth in the context of Nigeria, for instance, Emeka (2010) and Inuwa (2012). However, none of the studies applied Granger causality causality tests based on vector error correction model (VECM) to identify the short run as well as long causal relationship between the variables. Against this background, this paper aimed to re-examine the causality relationship between electricity consumption and economic growth, and to find out some policy implications from the results. To this achieve this, the following procedures are carried out. First, stationarity property of the variables are tested; second, Johansen maximum likelihood tests are estimated. Finally, Granger causality tests based on vector error correction model (VECM) are performed to examine the causality relationship between electricity consumption and economic growth.

The rest of the paper is organized as follows. Section 2 describes the electricity sector in Nigeria and Section 3 provides a review of literature related to electricity consumption and economic growth. Section 4 outlines the methodology used in the study. Following, Section 5 presents the empirical results of the research and the last section concludes the study.

\section{The Electricity Sector in Nigeria}

The electricity sector in Nigeria is presently characterized by chronic power shortages and poor power quality supply. With an approximated installed capacity of $6000 \mathrm{MW}$, it was stated that the country consumes about half its capacity. With an increased population coupled with 
diversification of economic activities, energy demand is rising but yet, electricity supply is relatively stagnant. It is therefore obvious that electricity demand is way above its supply thereby showing signs of potential economic growth (Odularo and Okonkwo, 2009).

Although, electricity in Nigeria is generated through three major sources: hydro, thermal and fossils. The electricity generation increased from less than 1000 mega watt per hour in 1980 to a little less than 3000 mega watt per hour in 2005. Electricity consumption on the other hand increased from little over 500 mega watt per hour in 1980 to 1873 mega watt per hour in 2005 although there was a sharp decline in consumption in 1998 and 1999. In relation to the volume of electricity generated, the country has over the years carried a lot of energy losses ranging from 43.1 to 41.5 per cent between 1980 and 2000. The figure however declined to 32.6 per cent in 2005 (Akinlo, 2009).

Since inception of NEPA in 1972, (renamed Power Holding Company of Nigeria, PHCN in year 2004) the authority expands annually in order to meet the ever-increasing demand. Unfortunately, majority of Nigerians have no access to electricity and the supply to those provided is not regular. It is against this backdrop that the federal government has embarked on aggressive power sector reforms with the intention of resuscitating PHCN and making it more efficient, effective and responsive to the yawning of the teeming populace (Obadote, 2009).

\section{Literature Review}

The link between electricity consumption and economic growth have received a great deal of attention from researchers. However, the direction of causality between electricity consumption and economic growth has remained empirically elusive and controversial across time, countries and methodologies. For example, Yusuf and Abdul Latif (2008) applied EngleGranger cointegration approach and standard Granger causality test for the period 1980-2006 on Malaysian data with a view to find the long run relationship and the direction of causality between electricity consumption and economic growth. Their findings revealed the presence of long run relationship between electricity consumption and economic growth as well as the absence causality relationship between the two variables. The authors also confirmed that the existing energy policies regarding electricity regulation policies will not have effect on economic growth in Malaysia. Similarly, Tang (2008) applied the newly developed autoregressive distributed lag (ARDL) model and modified Wald (MWALD) test for the quarterly data spanning from 1972:1-2003:4 interpolated using Gandolfo's interpolation technique for Malaysia. The result suggests that electricity consumption and economic growth are not cointegrated and also the 
MWALD test revealed a bidirectional relationship between the two variables contradicting the earlier findings.

Furthermore, Gupta and Sahu (2009) applied Granger causality test was to investigate the causality relationship between electricity consumption and economic growth for the period 1960-2006. The results suggests that electricity consumption has positive impact on economic growth implying that electricity consumption conservation policies have negative repercussions on Indian economy. Another study by Ghosh (2002) applied Johansen-Juselius maximum likelihood approach to cointegration tests and vector error correction model (VECM) for the period 1950-1997 and found the absence of long run relationship among the variables but there exists unidirectional Granger causality from economic growth to electricity consumption without feedback effect for India.

Moreover, Ciarreta and Zarrata (2007) applied Toda and Yamamoto non -Granger causality tests and standard Granger causality tests to analyze linear and non linear relationship between electricity consumption and economic growth for Spain during the period 1971-2005. The results revealed unidirectional linear causality running from economic growth to electricity consumption while no evidence of nonlinear causality between the variables in Spain. In another study, Altinay and Karagol (2005) examined the causal relationship between electricity consumption and real GDP in Turkey during the period of 1950 to 2000 and employed the DoladoLutkphol teat and standard Granger causality tests, both their test results exhibited unidirectional relationship running from electricity consumption and economic growth which implies that constant supply of electricity is inevitable to sustain economic growth in Turkey.

However, some empirical evidence were also emerged from Africa as Ouedraogo (2010) conducted an empirical study with a view to examine long run and causality relationship between electricity consumption and economic growth in Burkina Faso for the period 1968-2003 and applied ARDL bounds test technique and causality test by estimating a vector error correction model (VECM) within the ARDL framework. The bounds test evidenced the absence of long run relationship between electricity consumption and economic growth. The causality result indicated a long run bidirectional causal relationship between the two variables. Likewise, Odhiambo (2009), while conducting the causal relationship between electricity consumption and economic growth for the period 1971 to 2006 and applied a dynamic Granger causality test and Johansen-Jeselius maximum likelihood cointegration test. The author found a bidirectional causality between electricity and economic growth in South Africa.

In addition, a more recent study was conducted to examine the causal relationship between the electricity consumption and economic growth and 
employed ARDL bounds test and Granger causality test, Kouakou (2011) found a unidirectional relationship running from electricity consumption to economic growth in Code d' Ivoure. Another study on the long run relationship and causality between electricity consumption and GDP using Granger causality test and error correction model for the period 1970-1999 on Malawi's data, Jumbe (2004) reported bidirectional causality between electricity consumption and GDP suggesting that both the variables are jointly determined. The error correction model (ECM) revealed one-way causality running from GDP to electricity consumption implying that a permanent rise in GDP may cause a permanent growth in electricity consumption. Furthermore, Adom (2011) applied the Toda and Yamamoto Granger causality test via Seemingly Unrelated Regression (SUR) technique for the period of 1971 to 2008 on electricity consumption and real per capita GDP for Ghanian data. The results revealed that there exists a unidirectional causality running from economic growth to electricity consumption. Thus, electricity conservation measures will not have deteriorating effect on Ghanian economy.

Although many country specific studies have been conducted on causality issues related to electricity consumption and economic growth in energy economics literature, however, some empirical studies were also emerged on panel data basis. For example, Narayan and Prasad (2008) conducted a panel analysis on electricity consumption and economic growth on 30 OECD countries for the periods; 1970-2002 (USA); 1971-2002 (Slovak Republic and Korea); 1965-2002 (Hungary); while data for the rest of the OECD countries are for the period 1960-2002. Authors' applied bootstrapped causality techniques and found evidence of causality in favour of electricity consumption causing real GDP in Australia, Iceland, Italy, the Slovak Republic, the Czech Republic, Korea, Portugal and the UK. However, unidirectional causality was reported from real GDP to electricity consumption for the rest of the 22 OECD countries. Therefore the electricity conservation policies will negatively impact real GDP in the former countries while, electricity conservation policies will not affect real GDP in the latter countries.

In a recent study, Yoo and Kwak (2010) examined the causal relationship between electricity consumption and economic growth among seven South American countries and applied widely accepted Hsiao version of standard Granger causality test and error correction model (ECM) for the period 1975-2006. Their results revealed mixed causal relationship across countries. There is a unidirectional short run causal relationship from real GDP for Argentina, Brazil, Chile, Columbia, and Ecuador. This implies that an increase in electricity consumption directly affect economic growth in those countries. However, bidirectional relationship between electricity 
consumption and economic growth was reported for Venezuela, while no causality was detected in the case of Peru. Therefore, the results of causality from seven countries can provide useful information for each government with regard to energy and growth policy. More recent study was also conducted by Apergis and Payne (2011) on dynamic panel study of economic development and electricity consumption-growth nexus with a view to investigate the relationship between electricity consumption and economic growth for the 88 countries categorized into four panels based on the World Bank classification (high, upper middle, lower middle, and low income) over the period 1990-2006 and applied panel cointegration tests and panel causality tests. Their results from the panel vector error correction models were also categorized into four different panels. Firstly, bidirectional causality between electricity consumption and economic growth in both short- and long-run for the high income and upper-middle income country panels. Secondly, unidirectional causality from electricity to economic growth in the short-run, but bidirectional causality in the long-run for the lower-middle income country panel and thirdly, unidirectional causality from electricity consumption to economic growth for the low income country panel.

Moreover, Acaravci and Ozturk (2010) investigated electricity consumption-growth nexus from the panel of 15 transition countries for the period 1990-2006 and applied pedroni panel cointegration method and error correction based causality tests. The findings suggest that the panel cointegration tests do not report a long run relationship between electricity consumption and economic growth. Therefore, causality test through error correction model cannot be run. Thus, overall findings revealed no significant relationship between electricity consumption and real GDP in all 15 transition countries. Another study conducted using the newly ARDL bounds test technique based on unrestricted error correction model (UECM) and standard Granger causality test on OPEC countries for the period 19802003, Squalli (2007) found a long run relationship between electricity consumption and economic growth for all OPEC members. Causality has been evidenced from electricity consumption to economic growth in five countries (Indonesia, Iran, Nigeria, Qatar, and Venezuela), while causality runs from economic growth to electricity consumption for Algeria, Irag, and Libya and finally, neutrality hypothesis was justified for the remaining three countries.

\section{Methodology \\ Data}

The data used in this study consist of annual time series of RGDP and electricity consumption for Nigeria from 1980 to 2011. The choice of the 
starting period was constrained by the availability of data on electricity consumption. Both the RGDP and electricity consumption data were obtained from the World Bank's World Development Indicators (WDI, 2014). RGDP is used as proxy for economic growth and yearly electricity consumption is measured as KWh per capita.

\section{Unit Root Test}

In order to conduct the cointegration test, a series of variables need to be integrated of the same order or that the series contain a deterministic trend (Granger, 1988). In order to understand whether this condition is satisfied, the study applied Dickey- Fuller Generalized Least Square (DFGLS) unit root test.

\section{Cointegration Test}

Engle and Granger (1987) evidenced that if the two series $X$ and $Y$ integrated of same order i.e I(1) and cointegrated, then there would be a causal relationship in at least one direction. The presence of cointegration between the variables rules out the possibility of spurious results. But, If $X$ and $\mathrm{Y}$ each are non-stationary and cointegrated, then any standard Granger causality test will lead to spurious results. Therefore, alternative tests of causality based on an vector error-correction model and Toda and Yamamoto approach (1995) should be applied as suggested by Behmiri and Manso (2012). However, if X and Y are both non-stationary and the linear combination of the series of two variables is non-stationary then the standard Granger-causality test should be adopted. Therefore, it is necessary to test for the integration property of the series of electricity consumption and economic growth prior to performing the Granger-causality test. If both series are integrated of the same order, we can proceed to test for the presence of cointegration. The Johansen-Jeselius cointegration test procedure is used for this study.

\section{Granger Causality Test}

To examine the sources and directions of the causal relationship between the variables, vector error correction model (VECM) specified Granger causality test is applied. Specifically,VECM is employed to examine the Granger causality between per capita electricity consumption and per capita GDP of Nigeria. This is done via the following process: (i) Statistical significance of the lagged error correction terms (ECTs) by applying separate t-tests on the adjustment coefficients. The significance of ECT indicates the long-term causal effect. (ii) A Wald test is applied to the coefficients of the explanatory variable in one equation. For example, in the short run electricity consumption does not Granger cause economic growth if $\beta_{12 j}=0$ in equation 
(1). Alternatively, economic growth does not Granger-cause electricity consumption if $\beta_{22 j}=0$ in equation (2).

$\Delta R G D P_{t}=\beta_{10}+\sum_{i=1}^{k 11} \beta_{11 i} \Delta R G D P_{t-i}+\sum_{j=1}^{k 12} \beta_{12 j} \Delta E L T C_{t-j}+\beta_{13} E C T_{t-1}+\mu_{1 t}$

$\Delta E L T C_{t}=\beta_{20}+\sum_{i=1}^{k 21} \beta_{21 i} \Delta E L T C_{t-i}+\sum_{j=1}^{k 22} \beta_{22 j} \Delta R G D P_{t-j}+\beta_{23} E C T_{t-1}+\mu$

\section{Empirical Results}

Unit Root Test

The study started by testing for the order of integration for RGDP and electricity consumption before proceeding to testing for cointegration. Table 1 show the results of the unit root test on the natural logarithms of the levels and the first differences of the two time series viz. RGDP and electricity consumption. Based on the Dickey- Fuller Generalized Least Square (DFGLS) unit root test statistics, the null hypothesis of a unit root cannot be rejected. Stationarity is obtained by running the similar test on the first difference of the variables. This indicates that both the series are I(1) in nature.

Table 1: Unit Root Test

\begin{tabular}{lll}
\hline Variable & DF-GLS test at Level & DF-GLS test at first Difference \\
\hline RGDP & -1.328213 & $-5.029289^{* * *}$ \\
ELTC & -3.111398 & $-6.969135^{* * *}$ \\
\hline
\end{tabular}

Source: author's computations ***indicates level of significance at $1 \%$

\section{Cointegration Test}

Having found both the variables are integrated of order one i.e I(I). The next step is to find out whether the two variables are cointegrated, the study therefore applied the Johansen cointegration test. In Table 2 below, trace statistics and maximum Eigenvalue statistics indicate that the two variables (RGDP and ELTC) have one cointegrating relation or long-run equilibrium relationship both at $5 \%$ levels.

Table 2: Johansen-Juselius likelihood cointegration tests

\begin{tabular}{lcc}
\hline Number of Cointegration & Statistic & $5 \%$ critical value \\
\hline Trace Test & 20.57100 & 15.49471 \\
None & 0.143943 & 3.841466 \\
At most 1 & & \\
Max eigenvalue Test & 20.42705 & 14.26460 \\
None & 0.143943 & 3.841466 \\
At most 1 & Source & \\
\hline
\end{tabular}

Source: author's computations. 


\section{Granger Causality Test}

Table 3 below shows the results of causality test based on the VECM framework. The result of the short-run causality shows the $F$-statistics is statistically significant in the RGDP equation indicating short-run causality running from electricity consumption to economic growth. The long-run causality, on the other hand, is supported by the coefficient of the lagged error correction term, which is negative and statistically significant, also in the economic growth equation. Hence, the results evidenced a unidirectional causality running from electricity consumption to economic growth in both the short-and long run. This finding concur with the findings of Ahmad Golam and Nazrul Islam (2011) for Bangladesh, Akinlo (2009) for Nigeria and Gupta and Sahu (2009) for India. This result therefore suggests that electricity consumption stimulates the growth of Nigerian economy and any electricity conservation measures will be detrimental to economic growth.

Table3 Granger Causality Based on Vector Error Correction Model (VECM)

\begin{tabular}{|c|c|c|c|}
\hline Dependent Variable & $\begin{array}{l}\text { Short run } \\
\Delta \text { RGDP }\end{array}$ & $\triangle$ ELTC & Long-run \\
\hline$\Delta \mathrm{RGDP}$ & $3.286(0.053)$ & - & $-0.108(0.05)$ \\
\hline$\triangle \mathrm{ELTC}$ & - & $1.746(0.194)$ & $0.375(0.00)$ \\
\hline
\end{tabular}

Source: author's computations.

\section{Conclusion and Policy Implication}

This study has explored the dynamic relationship between economic growth and electricity consumption using time series data for the period of 1980-2011. In doing so, the DF-GLS unit root test is used to test the order of integration of the variables. Johansen maximum likelihood test approach to cointegration is applied to investigate long run relationship and vector error correction model (VECM) to examine causality between the variables.The results confirmed the cointegration which further validates the existence of long run relationship between economic growth and electricity consumption. The Granger causality tests revealed unidirectional causality running from electricity consumption to economic growth in both the short- and long run without feedback. Therefore, electricity consumption causes economic growth. This implies that the increase in electricity consumption can be viewed as a leading indicator of growing economy. The study conclude that the Nigerian economy will be electricity dependent in the long run and therefore any conservation policy would have negative effects on economic growth. Thus, the study recommends that the government should design policies aimed at improving electricity production and even create new electricity sources. 


\section{References:}

Adom, P. K. (2011). "Electricity Consumption-Economic Growth Nexus: The Ghanian Case". International Journal of Energy Economics and Policy, $1(1), 18-31$.

Altinay, G. and Karagol, E. (2005). "Electricity Consumption and Economic Growth: Evidence from Turkey.” Energy Economics, 27(6), 849-856.

Apergis, N and Payne, J. (2011). "A Dynamic Panel Study of Economic Development and the Electricity Consumption-Growth Nexus." Energy Economics, 33, 770-781.

Akinlo, A. E. (2009). "Electricity Consumption and Economic Growth in Nigeria: Evidence from Cointegration and Co-feature Analysis." Journal of Policy Modeling, 31(5), 681-693.

Behmiri, N.B. and Manso, J.R.P. (2012): "Does Portuguese Economy Support Crude Oil Conservation Hypothesis?." Energy, 45, 628-634.

Ciarreta, A. and Zarrata, A. (2007). "Electricity Consumption and Economic Growth: Evidence from Spain. Documto de Trebajo, 01.

Engle, R.F., and Granger, C.W.J. (1987): "Co-integration and error correction: representation, estimation and testing". Econometrica, 55 (2), 251-276.

Gupta, G and Sahu, N.C. (2009). "Causality Between Electricity Consumption and Economic Growth: Empirical Evidence from India.' MPRA Paper, No. 22942.

Ghosh, S. (2002). "Electricity Consumption and Economic Growth in India." Energy Policy, 30(2), 125-129.

Granger, C.W.J. (1988): "Some recent developments in a concept of causality". Journal of Econometrics, 39 (1-2), 199-211

Iwayemi, A. (2008). "Investment in Electricity Generation and Transmission in Nigeria: Issue and Option." International Association for Energy Economics, 37-42.

Jumbe, C.B.L. (2004). "Cointegration and Causality Between Electricity Consumption and GDP: Empirical Evidence from Malawi." Energy Economics, 26, 61-68.

Kouakou, A. K. (2011). " Economic Growth and Electricity Consumption in Code d'Ivoire: Evidence from Time Series Analysis.” Energy Policy, 36383644.

Narayan, P.K. and Prasad, A. (2008). "Electricity Consumption-Real GDP Causality Nexus: Evidence from a Bootstrapped Causality Test for 30 OECD Countries." Energy Policy, 36(2), 910-918.

Odularo, G. O. and Okonkwo, C. (2009). "Does Energy Consumption Contribute to Economic Performance? Empirical Evidence from Nigeria," Journal of Economics and International Finance, 1(2), 044-058. 
Obadote, D. J. (2009). “ Energy Crisis in Nigeria: Technical Issues and Solutions." Power Sector Prayer Conference.

Ouedraogo, I. M. (2009). "Electricity Consumption and Economic Growth in Burkina Faso: Cointegration Analysis." Energy Economics, 32(3), 849-856.

Odhiambo, N. M. (2004). "Electricity Consumption and Economic Growth in South Africa:A Trivariate Causality Test. Energy Economics,31(5), 635640.

Ozturk, I and Acaravci, A. (2010). "The Causal Relationship Between Energy Consumption and GDP : Evidence from Panel Data for Transition Countries." Energy Economics, 32(3), 1938-1943.

Squalli, J. (2007). "Electricity Consumption and Economic Growth: Bounds and Causality Analysis for OPEC Members." Energy Economics, 29, 11921205.

Shahbaz, M., Tang, C.F. and Shabbir, M.S. (2011). "Electricity Consumption and Economic Growth Nexus in Portugal using Cointegration and Causality Approaches." Energy Policy, 39, 3529-3536.

Tang, C. F. (2008). "A re-examination of the Relationship Between Electricity Consumption and Economic Growth in Malaysia." Energy Policy, 36(8), 3077-3085.

Toda, H.Y. and Yamamoto, T. (1995): "Statistical inference in vector autoregressions with possibly integrated processes". Journal of Econometrics, 66, 225-250.

Yusuf, M.Y.N and AbdulLatif, N.W (2008). " Causality Between Electricity Consumption and Economic Growth in Malaysia: Policy Implications."

Yoo, S.H. and Kwak, S. Y. (2010). "Electricity Consumption and Economic Growth in Seven South American Countries." Energy Policy, 34, 3573-3582. 